\title{
The role of the winter residual circulation in the summer mesopause regions in WACCM
}

\author{
Maartje Sanne Kuilman and Bodil Karlsson \\ Department of Meteorology, Stockholm University, 10691 Stockholm, Sweden \\ Correspondence: Maartje Sanne Kuilman (maartje.kuilman@misu.su.se)
}

Received: 9 July 2017 - Discussion started: 11 September 2017

Revised: 14 February 2018 - Accepted: 23 February 2018 - Published: 28 March 2018

\begin{abstract}
High winter planetary wave activity warms the summer polar mesopause via a link between the two hemispheres. Complex wave-mean-flow interactions take place on a global scale, involving sharpening and weakening of the summer zonal flow. Changes in the wind shear occasionally generate flow instabilities. Additionally, an altering zonal wind modifies the breaking of vertically propagating gravity waves. A crucial component for changes in the summer zonal flow is the equatorial temperature, as it modifies latitudinal gradients. Since several mechanisms drive variability in the summer zonal flow, it can be hard to distinguish which one is dominant. In the mechanism coined interhemispheric coupling, the mesospheric zonal flow is suggested to be a key player for how the summer polar mesosphere responds to planetary wave activity in the winter hemisphere. We here use the Whole Atmosphere Community Climate Model (WACCM) to investigate the role of the summer stratosphere in shaping the conditions of the summer polar mesosphere. Using composite analyses, we show that in the absence of an anomalous summer mesospheric temperature gradient between the equator and the polar region, weak planetary wave forcing in the winter would lead to a warming of the summer mesosphere region instead of a cooling, and vice versa. This is opposing the temperature signal of the interhemispheric coupling that takes place in the mesosphere, in which a cold and calm winter stratosphere goes together with a cold summer mesopause. We hereby strengthen the evidence that the variability in the summer mesopause region is mainly driven by changes in the summer mesosphere rather than in the summer stratosphere.
\end{abstract}

\section{Introduction}

The circulation in the mesosphere is driven by atmospheric gravity waves (GWs). These waves originate from the lower atmosphere and as they propagate upwards, they are filtered by the zonal wind in the stratosphere (e.g. Fritts and Alexander, 2003). Because of the decreasing density with altitude and as a result of energy conservation, the waves grow in amplitude. At certain altitudes, the waves - depending on their phase speeds relative to the background wind - become unstable and break. At the level of breaking, the waves deposit their momentum into the background flow, creating a drag on the zonal winds in the mesosphere, which establishes the pole-to-pole circulation (e.g. Lindzen, 1981; Holton, 1982, 1983; Garcia and Solomon, 1985). This circulation drives the temperatures far away from the state of radiative balance, by adiabatically heating the winter mesopause and adiabatically cooling the summertime mesopause (Andrews et al., 1987; Haurwitz, 1961; Garcia and Solomon, 1985; Fritts and Alexander, 2003). The adiabatic cooling in the summer leads to temperatures sometimes lower than $130 \mathrm{~K}$ in the summer polar mesopause (Lübken et al.,1990). These low temperatures allow for the formation of thin ice clouds, the so-called noctilucent clouds (NLCs).

Previous studies have shown that the summer polar mesosphere is influenced by the winter stratosphere via a chain of wave-mean-flow interactions (e.g. Becker and Schmitz, 2003; Becker et al., 2004; Karlsson et al., 2009). This phenomenon, termed interhemispheric coupling (IHC), manifests itself as an anomaly of the zonal mean temperatures. Its pattern consists of a quadrupole structure in the winter hemisphere with a warming (cooling) of the polar stratosphere and an associated cooling (warming) in the equatorial stratosphere. In the mesosphere, these anomalies are re- 
versed: there is a cooling (warming) in the polar mesosphere, and an associated warming (cooling) in the equatorial region. The mesospheric warming (cooling) in the tropical region extends to the summer mesopause (see e.g. Körnich and Becker, 2010).

These anomalies are responses to different wave forcing in the winter hemisphere. In order to explain how these anomalies come about, we here briefly summarize the IHC mechanism for the case when the winter stratosphere is dynamically active, i.e. for a stratospheric meridional flow that is anomalously strong. The mechanism works in reverse when the meridional circulation in the stratosphere is anomalously weak. A stronger planetary wave (PW) forcing in the winter stratosphere yields a stronger stratospheric Brewer-Dobson circulation (BDC). This anomalously strong flow yields an anomalously cold stratospheric tropical region and a warm stratospheric winter pole, due to the downward control principle (Karlsson et al., 2009).

Due to the eastward zonal flow in the winter stratosphere, GWs carrying westward momentum propagate relatively freely up into the mesosphere where they break. Therefore, in the winter mesosphere, the net drag from GW momentum deposition is westward. When vertically propagating PWs break - also carrying westward momentum - in the stratosphere, its momentum deposited onto the mean flow, which decelerates the stratospheric westerly winter flow. To put it short, a weaker zonal stratospheric winter flow allows for the upward propagation of more GWs with an eastward phase speed, which, as they break, reduces the westward wave drag (see Becker and Schmitz, 2003, for a more rigorous description).

This filtering effect of the zonal background flow on the GW propagation results in a reduction in strength of the winter-side mesospheric residual circulation when the BDC is stronger. This weakened meridional flow causes the mesospheric polar winter region to be anomalously cold and the tropical mesosphere to be anomalously warm (Becker and Schmitz, 2003; Becker et al., 2004; Körnich and Becker, 2009).

The critical step for IHC is the crossing of the temperature signal over the equator. The essential region is here the equatorial mesosphere. Central to the hypothesis of IHC is that the increase (or decrease) of the temperature in the tropical mesosphere modifies the temperature gradient between high and low latitudes in the summer mesosphere, which influences the zonal wind in the summer mesosphere, due to thermal wind balance (see e.g. Karlsson et al., 2009; Karlsson and Becker, 2016).

The zonal wind change in the summer mesosphere modifies the breaking level of the summer side GWs. In the case of a warming of the equatorial mesosphere - when the BDC is strong - the zonal wind is modified in such a way that the intrinsic wave speeds are reduced (e.g. Becker and Schmitz, 2003; Körnich and Becker, 2009). Consequently, the GWs break at a lower altitude and over a broader altitude range (see Becker and Schmitz, 2003), thereby shifting down the GW drag per unit mass. Hence, the strength of the meridional flow is reduced, and the adiabatic cooling of the summer polar mesopause region decreases, resulting in a positive anomalous temperature response (Karlsson et al., 2009; Körnich and Becker, 2009; Karlsson and Becker, 2016). In the case of an equatorial mesospheric cooling, the response is the opposite: the relative difference between the zonal flow and the phase speeds of the GWs increase so that they break at slightly higher altitudes, with an anomalous cooling of the summer polar mesopause as a result.

The IHC pattern was first found using mechanistic models (Becker and Schmitz, 2003) underpinned by observations of mesospheric conditions (Becker et al., 2004; Becker and Fritts, 2006). The pattern was then found in observational data (e.g. Karlsson et al., 2007; Gumbel and Karlsson, 2011; Espy et al., 2011; De Wit et al., 2016), in the Whole Atmosphere Community Climate Model (WACCM; Sassi et al., 2004; Tan et al., 2012), in the Canadian Middle Atmosphere Model (CMAM; Karlsson et al. 2009), and in the highaltitude analysis from the Navy Operational Global Atmospheric Prediction System - Advanced Level Physics High Altitude (NOGAPS-ALPHA) forecast/assimilating system (Siskind et al., 2011).

As described above, the temperature in the equatorial mesosphere is modified by the strength of the residual circulation in the winter mesosphere. Karlsson and Becker (2016) showed that the equatorial mesosphere is substantially colder in July than it is in January, while the winter mesosphere is significantly warmer (see their Fig. 1). They proposed that this cooling of the equatorial region - caused by the strong mesospheric winter flow - modifies the breaking levels of the summer GWs throughout the July season, leading to additional cooling of the summer polar mesopause region. If - as hypothesized by Karlsson and Becker (2016) the fundamental effect of the IHC is a cooling of the summer polar mesopauses, it would mean that the mechanism plays a more important role affecting the temperatures in the summer mesopause in the Northern Hemisphere (NH) compared to that in the Southern Hemisphere (SH), since the weaker PW activity in the SH results in an increased GW drag and a strengthening of mesospheric poleward flow in the winter mesosphere. The equatorial mesosphere is adiabatically cooled more efficiently than when the winter mesospheric circulation is weak. Karlsson and Becker (2016) further hypothesized that in the absence of the equator-to-pole flow in the SH winter, the summer mesopause in the $\mathrm{NH}$ would be considerably warmer. To test the hypothesis, they used the KMCM (Kühlungsborn Mechanistic general Circulation Model) to compare control simulations to runs without GWs in the winter mesosphere. The predicted responses were confirmed, and the results were also backed up by correlation studies using the Canadian Middle Atmosphere Model (CMAM30). 
The IHC mechanism - as described above - is not the only driver of variability in the summer polar mesopause region. Another common feature in the summer mesosphere is the quasi 2-day wave (Q2DW; see e.g. Pendlebury, 2012), which is generated by baroclinic instability linked to the shear of the easterly flow in the summer stratosphere $(\mathrm{Wu}$ et al., 1996). Since variability in the summer stratospheric zonal flow is also related to the IHC mechanism, the two phenomena should be closely coupled, as suggested by $\mathrm{Gu}$ et al. (2016). An indication of their interconnection is given by the following studies: (a) Karlsson et al. (2007) found a strong anticorrelation between the noctilucent cloud occurrence and high-latitude winter stratospheric temperatures and (b) Siskind and McCormack (2014) sought revision of the theory behind the IHC since they could not find indications of the conventional temperature and wind patterns associated with the proposed IHC mechanism. In the light of these findings, we hypothesize that while the Q2DW is associated with an enhanced PW activity in the winter hemisphere as suggested by e.g. Salby and Challaghan (2001) and shown by Gu et al. (2016) - and could plausibly be one of the main drivers of warming events in the summer mesosphere, particularly the SH summer (see e.g. Gu et al., 2015) - it cannot completely replace the conventional IHC. The two main arguments are the following:

i. The Q2DW does not explain why calm conditions in the winter stratosphere generate anomalously cold conditions in the summer mesosphere (e.g. Karlsson et al., 2009; Karlsson and Becker, 2016).

ii. If it were only the Q2DW that generated warming events in the summer mesosphere, these events would be insensitive to the residual circulation in the mesosphere. Strong PW activity leading to acceleration of the summer stratospheric jet - via a sharpened summer stratospheric temperature gradient - would generate baroclinic instability independently of the circumstances in the winter mesosphere. Therefore, removing GWs in the winter would not influence the summer mesospheric response. We test this hypothesis in this study by compositing monthly-mean winters of high and low PW activity and comparing the outcomes with and without winter GWs. These results are presented in Sect. 3.2.

Since IHC is controversial, we find it important to use as many tools as possible to test - and to underpin - our arguments. In this study, the well-established WACCM, described in Sect. "Model" below, is used to endorse the results obtained with the not as widely used - yet high performing - KMCM. WACCM is in some aspects a more comprehensive model than KMCM. For example, a major difference is that WACCM contains interactive chemistry in the middle atmosphere, while KMCM does not. WACCM also uses a different parameterization for non-orographic GWs than KMCM. KMCM uses a simplified dynamical core and con- vection scheme as compared to WACCM. For details about KMCM see e.g. Becker et al. (2015). The WACCM is described in Sect. 2. In Sect. 3, we present the results from removing the GWs in the winter hemisphere on the summer mesosphere region in WACCM. Comparisons to the Karlsson and Becker (2016) study are discussed in Sect. 3.1. In Sect. 3.2 we examine the role of the summer stratosphere in shaping the conditions of the polar mesosphere when the winter mesospheric flow is absent. Our conclusions are summarized in Sect. 4.

Since the IHC mechanism has a more robust signal in the SH winter-NH summer, we choose to focus particularly on this period, namely July. Nevertheless, results from January are also shown for comparisons and for further discussion.

\section{Method}

\section{Model}

The Whole Atmosphere Community Climate Model (WACCM) is a so-called "high-top" chemistryclimate model, which spans the range of altitudes from the Earth's surface to an altitude of about $140 \mathrm{~km}$. WACCM has 66 vertical levels of a resolution of $\sim 1.1 \mathrm{~km}$ in the troposphere above the boundary layer, $1.1-1.4 \mathrm{~km}$ in the lower stratosphere, $1.75 \mathrm{~km}$ at the stratosphere and $3.5 \mathrm{~km}$ above $65 \mathrm{~km}$. The horizontal resolution is $1.9^{\circ}$ latitude by $2.5^{\circ}$ longitude (Marsh et al., 2013).

The model is a component of the Community Earth System Model (CESM), which is a group of model components at the National Center for Atmospheric Research (NCAR). WACCM is a superset of the Community Atmospheric Model version 4 (CAM4) and as such it includes all the physical parameterizations of CAM4 (Neale et al., 2013).

WACCM includes parameterized non-orographic GWs, which are generated by frontal systems and convection (Richter et al., 2010). The orographic GW parameterization is based on McFarlane (1987), while the non-orographic GW propagation parameterization is based on the formulation by Lindzen (1981).

In this study, the F_2000_WACCM (FW) compset (component set) of the model is used, i.e. the model assumes present-day conditions. There is no forcing applied: the model runs a perpetual year 2000. Our results are based on a control run and perturbation runs. In the control run, the winter-side residual circulation is included. In the perturbation runs, the equator-to-pole flow is removed by turning off both the orographic and the non-orographic GWs. It should, however, be noted that even though the GWs are turned off, there are still some resolved waves, such as inertial GWs and PWs that drive a weak meridional circulation. The model is run for 30 years. 

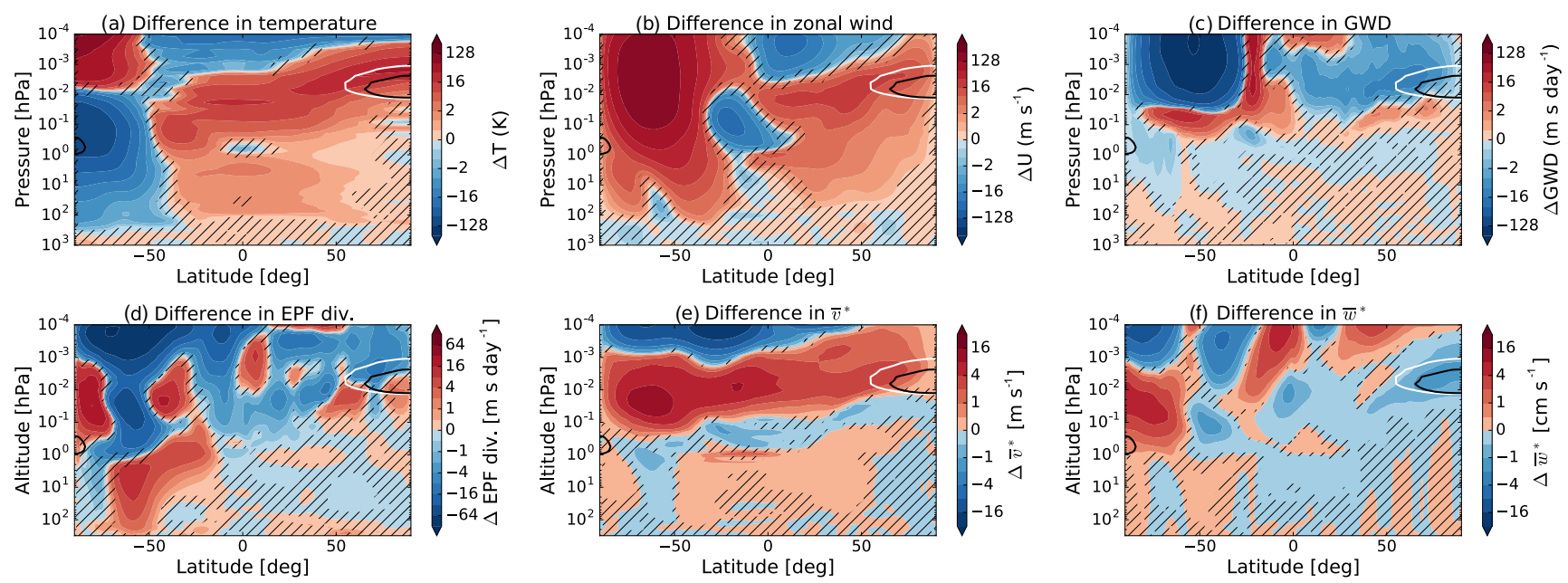

Figure 1. The difference in zonal-mean temperature (a), zonal-mean zonal wind (b), gravity wave (GW) drag (c), EP flux divergence (d) and the transformed Eulerian-mean residual circulation velocity $\bar{v}^{*}$ (e) and $\bar{w}^{*}$ (f) for July: (run without winter GWs) minus (control run). The white contour indicates the summer polar mesopause region where the temperatures are below $150 \mathrm{~K}$ for the control run. The black contour indicates the region where the temperature is below $150 \mathrm{~K}$ for the run without the GWs in winter. The hatched areas are regions where the data does not reach a confidence level of $95 \%$.

\section{Results and discussion}

\subsection{The effect of the winter residual circulation on the summer mesopause}

To investigate the effect of the winter residual circulation on the summer mesopause, we compare the control run, which includes winter GWs, with the perturbation runs. In the perturbation runs, the residual flow is removed by turning off the parameterized GWs in the winter hemisphere. The resolved waves, such as tides, inertial GWs and PWs are still there and drive a weak poleward flow, as already described in Sect. "Model".

We start by investigating the case for the $\mathrm{NH}$ summer (July) with the GWs turned off for the SH, where it is winter. Figure 1 shows the difference in zonal-mean temperature, zonal wind and GW drag for July as a function of latitude and altitude, between the control run and the perturbation run: the run without the GWs in the winter minus the run with the GWs in the SH.

From Fig. 1a, it is clear that there is a considerable increase in temperature in the $\mathrm{NH}$ summer mesopause region in the case for which there is no equator-to-pole flow in the $\mathrm{SH}$ winter. This change in temperature in the summer polar mesosphere can be understood as a result of changes in the wave-mean-flow interactions. Without the GWs in the SH winter, the winter stratosphere and lower mesosphere are colder. This is because GWs in the winter hemisphere drive downwelling, adiabatically heating these regions (e.g. Shepherd, 2000).

Turning off the GWs in winter hemisphere changes the meridional temperature gradient in the summer hemisphere, as the equatorial mesosphere will be warmer. Thereby - via thermal wind balance - the zonal mesospheric winds are modulated. It is also clear that the zonal flow at high latitudes accelerates for the case where there is no meridional flow in the SH winter. These findings correspond with what is found in Karlsson and Becker (2016).

Figure 1a shows a significant warming in the equatorial mesosphere as well as in the stratosphere in the case where there are no GWs in the winter hemisphere, indicating a weakening of the BDC. We suggest that the warming of the tropical stratosphere could be due to a redistribution of PW momentum drag in the winter stratosphere: without GWs in the mesosphere, breaking levels of the westward propagating PWs are shifted upwards. Hence, the PW drag will be distributed over a wider altitude range. Our results show that this is indeed the case for the positive meridional heat flux (not shown). Another contributor to a decrease in the BDC is the removal of the orographic GWs, which act as PWs on the zonal flow in the winter stratosphere (see e.g. Karlsson and Becker, 2016; their Fig. 7).

The anomalously eastward flow in the summer upper stratosphere/lower mesosphere leads to lower GW levels and weaker GW drag over $45-70^{\circ} \mathrm{N}$ above a pressure level of $0.02 \mathrm{hPa}$ as can be seen in Fig. $1 \mathrm{~b}$ and c. This causes the summer polar mesopause to be considerably warmer. The temperature increase in the summer polar mesopause region, which is now loosely defined to be between $61-90^{\circ} \mathrm{N}$ and $0.01-0.002 \mathrm{hPa}$, is approximately $16 \mathrm{~K}$. In a solely radiationdriven atmosphere, the temperature in the summer polar mesosphere is about $210-220 \mathrm{~K}$, which is much higher than the temperature both with and without the GWs in the SH. 

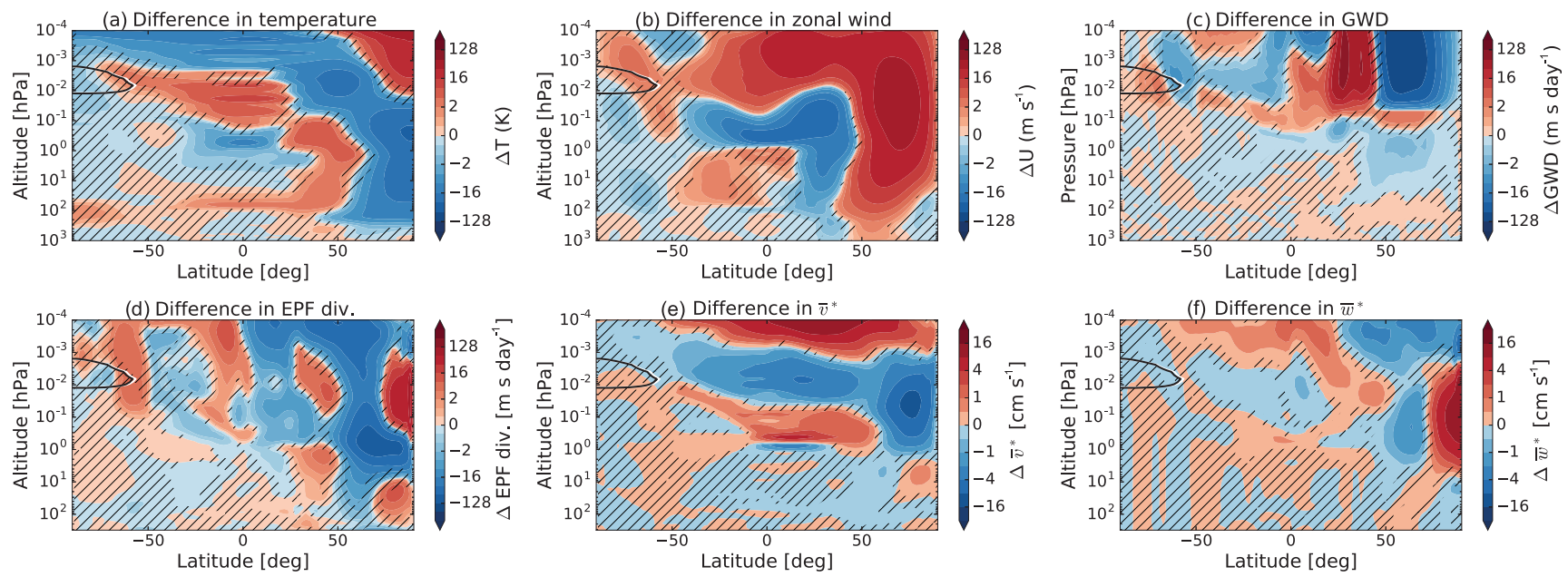

Figure 2. Same as Fig. 1, but for January.

When comparing our results with the results in Karlsson and Becker (2016, their Fig. 3), we observe there are some quantitative discrepancies in the structure of the responses. For example, Karlsson and Becker (2016) found that removing the winter GWs resulted in a warming of the upper mesosphere globally, although the response was strongest in the polar mesopause region. They attributed the warming over the upper equatorial and winter mesosphere to the effect that GWs have on tides: when GWs are absent, the tidal response is enhanced. The same behaviour is not found in WACCM - in fact the equatorial upper mesosphere is anomalously cooler when the GWs are removed. These differences could perhaps be explained by, for example, the different GW parameterization of non-orographic GWs, the different dynamical cores between the models and the presence of interactive chemistry in the middle atmosphere in WACCM.

However, the upper mesospheric response is not affecting the mechanism we are discussing in this study. Thus we do not consider the upper mesosphere region in the rest of the paper. The qualitative response of the temperature and zonal wind change in the stratosphere and lower parts of the mesosphere due to turning off the GWs in the SH corresponds well with the results from the KMCM as well as with the current hypothesis.

It can also be seen that in accordance with the results from the KMCM, the zonal wind and temperature in the summer stratosphere region change only slightly in the perturbation runs as compared to the control runs. We deem that anomalous GW filtering effects from lower down in the summer stratosphere, which could affect the results, are unlikely to contribute substantially to the temperature change in the summer mesosphere. We come back to this question in Sect. 3.2.

Removing the GWs in the winter hemisphere leads to changes in the Eliassen-Palm (EP) flux divergence and in the residual circulation velocities $\bar{v}^{*}$ and $\bar{w}^{*}$. Figure 1d shows that the EP flux divergence is changed mostly in the winter hemisphere, as expected, because of the removal of GWs. The EP flux divergence increases in the stratosphere and decreases at higher altitudes. This could, as mentioned previously, be a result of the change in the zonal wind, which modifies the propagation and breaking of PWs in the winter stratosphere.

Figure 1e and $\mathrm{f}$ show the changes in the residual circulation velocities. Again it is the winter hemisphere which is mostly affected. As expected, for the case without GWs in the winter hemisphere, there is less southward flow as seen in Fig. 1e. At the same time $\bar{w}^{*}$ changes throughout the winter stratosphere and mesosphere, as seen in Fig. 1f. There is a significantly stronger upwelling in the summer polar mesopause region as well as in the tropical mesosphere for the case when the GWs are included as compared to when they are absent (manifested by the negative anomalous response).

As pointed out before, the effect of removing winter GWs on the summer polar mesopause will be smaller in January than in July since the SH winter residual circulation is stronger than the NH summer mesosphere in July. Figure 3 shows the difference in zonal-mean temperature, zonal wind and GW drag for January as a function of latitude and altitude, between the control run and the perturbation run: the run without the GWs in the $\mathrm{NH}$ winter hemisphere minus the run with the GWs in the $\mathrm{NH}$ winter hemisphere (similar to Fig. 1).

From Fig. 2a, it can be observed that, in WACCM, there is no statistically significant temperature change in the $\mathrm{SH}$ summer polar mesopause region in the case for which there is no equator-to-pole flow in the $\mathrm{NH}$ winter. Without the GWs in the winter hemisphere, the winter stratosphere and lower mesosphere are colder, as in the July case. There is a change 

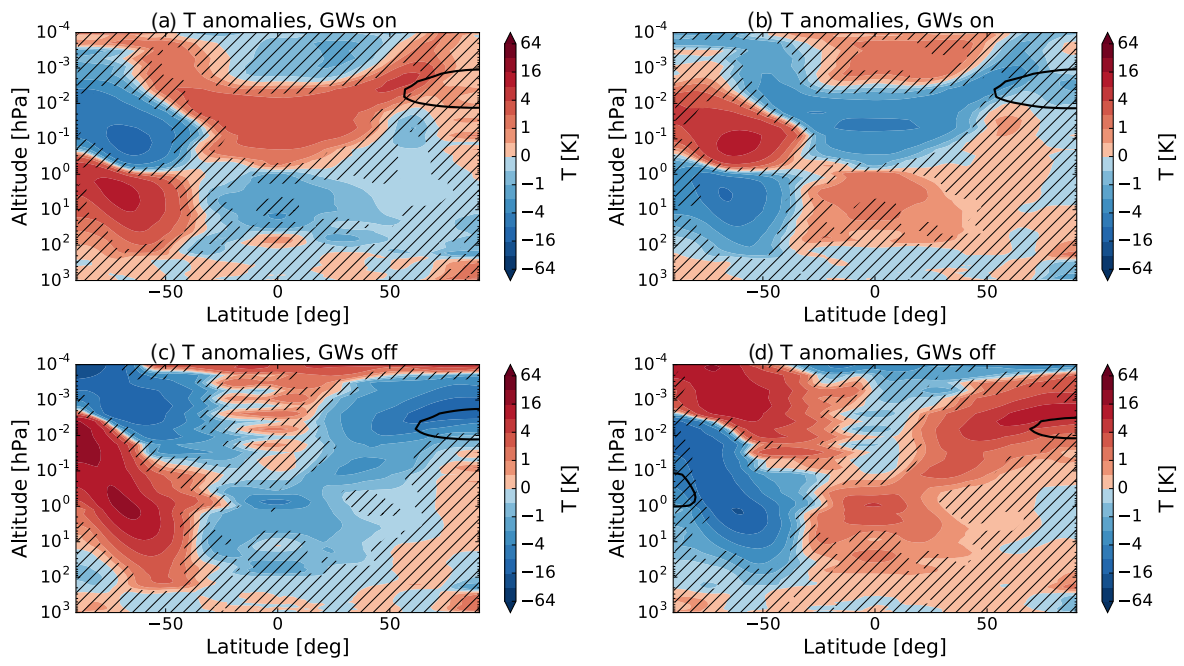

Figure 3. The temperature anomalies for high $(\mathbf{a}, \mathbf{c})$ and low $(\mathbf{b}, \mathbf{d})$ planetary wave $(\mathrm{PW})$ activity, as measured by the temperature in the winter stratosphere $\left(1-10 \mathrm{hPa}, 60-40^{\circ} \mathrm{S}\right)$ in July for the control run $(\mathbf{a}, \mathbf{b})$ and run without GWs in the winter hemisphere (c, d). There are 10 years of data with high temperature anomalies and 9 years with low temperature anomalies in the winter stratosphere, this is the case for both the runs with and without the GWs in the winter hemisphere. The hatched areas are regions where the data does not reach a confidence level of $95 \%$. The black $150 \mathrm{~K}$ contour indicates the polar mesopause region.

in zonal wind at high southern latitudes, but there is no clear statistically significant increase. These findings correspond with what is hypothesized in the introduction: taking away the GWs in the $\mathrm{NH}$ winter will have a weaker effect on the SH summer mesopause than taking away the GWs in the $\mathrm{SH}$ winter on the NH summer mesopause. This is plausibly partly due to the variable nature of the winter stratosphere zonal flow in the $\mathrm{NH}$, which oscillates between being weak and strong. As a result, the January equatorial mesosphere is modified continuously: it varies between being adiabatically cooled and being heated by the winter mesospheric residual flow. In July, on the other hand, the equatorial region is continuously cooled by the strong mesospheric residual flow in the SH winter. Hence, as already proposed by Karlsson and Becker (2016) the IHC mechanism gives one plausible explanation as to why the July summer mesosphere region is considerably colder than the one in January.

We again show the effect of removing the GWs in the winter hemisphere on the EP flux divergence and on the residual circulation velocities $\bar{v}^{*}$ and $\bar{w}^{*}$. Figure $3 \mathrm{~d}$ shows the difference in EP flux divergence, the pattern in the mesospheric response is similar to the response in July. Also, the general patterns of the changes in residual circulation velocities (see Fig. $3 e$ and f) look similar but are in general a bit smaller than in the July case, which we expected. Note the change of sign in $\bar{v}^{*}$, this is because the mesospheric flow in January is northwards as opposed to the flow in July.

A comparison between the responses found using WACCM with those found with KMCM (Karlsson and Becker, 2016, their Fig. 3) shows that the temperature change is larger and extends all the way to the summer pole in
KMCM, while this is not the case in WACCM. However, the change in temperature in this region is not statistically significant in WACCM. The differences in temperature and zonal wind responses are larger in January than in July when comparing the results of WACCM with that of KMCM. Nevertheless, the qualitative structure of the temperature and zonal wind change due to turning off the winter GWs corresponds convincingly well.

IHC has hitherto primarily been seen as a mode of internal variability giving rise to a warming of the summer mesopause region. These results presented here and in Karlsson and Becker (2016) show the more fundamental role of IHC; the mechanism has a net cooling effect on the summer mesosphere.

\subsection{The effect of the summer stratosphere region on the summer mesopause}

The summer stratospheric meridional temperature gradient is affected by the strength of Brewer-Dobson circulation. Hence, filtering effects taking place below the mesosphere could be an additional - or alternative - mechanism to the response observed in the summer mesopause. Moreover, the Q2DW is amplified as a result of baroclinic instability associated with a strengthening of the easterly jet in the summer stratosphere (e.g. Gu et al., 2016). If Q2DWs were the sole reason for summer polar mesospheric warming events at dynamically active winters, the response would still hold after removing winter GWs. In this section, we will discuss why the variability in the summer stratosphere is unlikely to be the main driver for year-to-year temperature responses in the 

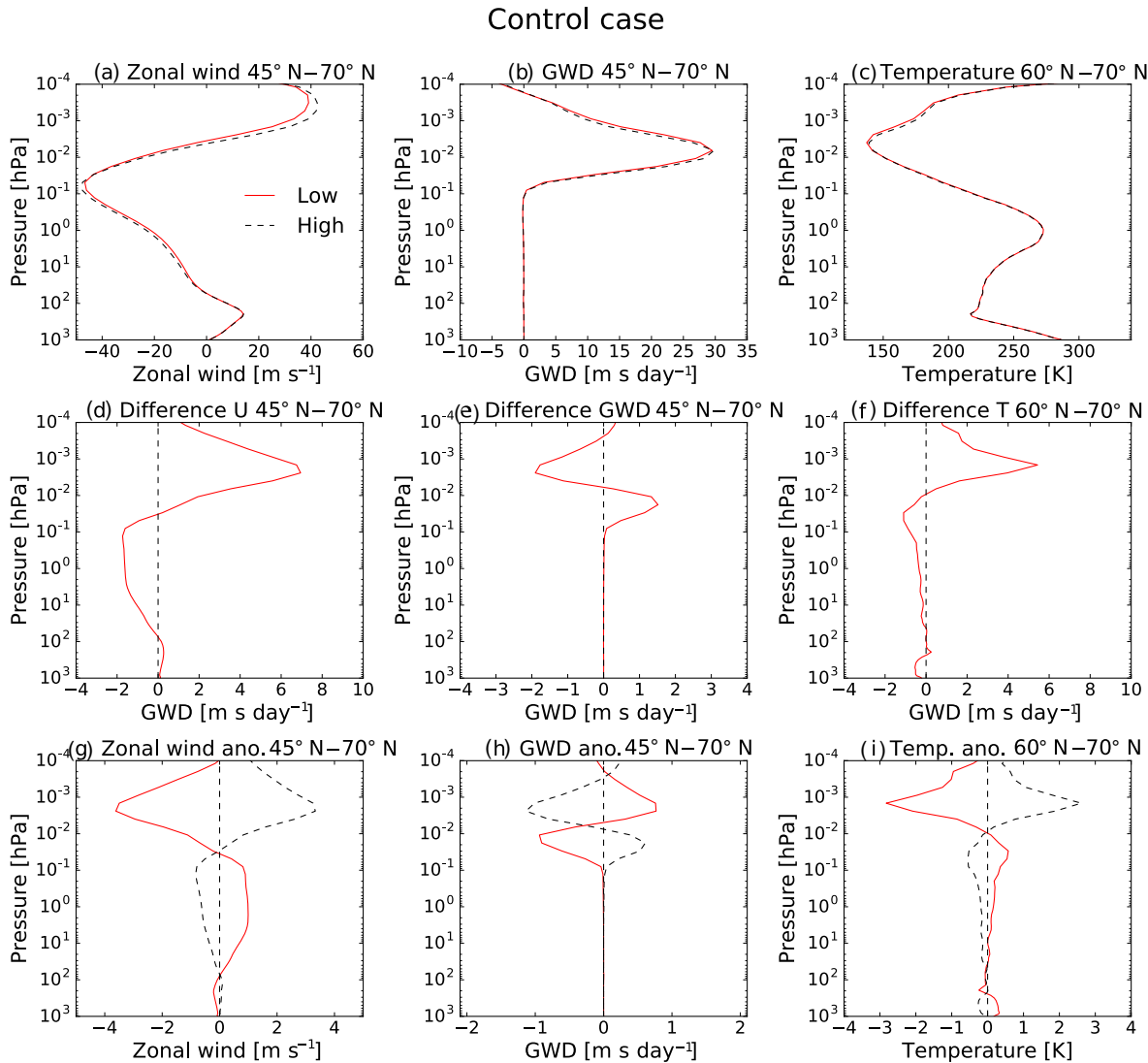

Figure 4. The July zonal wind (a, d, g) and the GW drag (b, e, h) between $45-70^{\circ} \mathrm{N}$ and the temperature (c, f, i) between $70-90^{\circ} \mathrm{N}$ for anomalously low and high temperatures in the winter stratosphere $\left(1-10 \mathrm{hPa}, 60-40^{\circ} \mathrm{S}\right)(\mathbf{a}-\mathbf{c})$ and the differences between them $(\mathbf{d}-\mathbf{f})$ and their anomalies $(\mathbf{g}-\mathbf{i})$, for the case where there are GWs in the winter hemisphere. The red continuous lines show the results for anomalously low temperatures and the black dashed lines show the results for the anomalously high temperatures.

summer polar mesosphere. We focus again mostly on the $\mathrm{NH}$ summer polar mesosphere region.

In Fig. 3, the results from compositing years of high (a) and years of low (b) temperature anomalies, indicating high and low PW activity, in the winter stratosphere in July (1$10 \mathrm{hPa}, 60-40^{\circ} \mathrm{S}$ ) are shown for cases when GWs are present (upper panels) and absent (lower panels) in the winter hemisphere. Thresholds for the temperature anomalies are set as lower than half a standard deviation under the mean for the low temperature anomalies, and higher than half a standard deviation above the mean for the high temperature anomalies. As can be seen in the temperature responses associated with PW activity, the NH summer polar mesosphere is responding with the same anomalous sign as the high latitude winter stratosphere when winter GWs are included (Fig. 3a and $b$ ). This is in agreement with the results presented in Karlsson et al. (2009) although the WACCM temperature response does not reach statistical significance at a $95 \%$ level all the way to the polar region. This could be due to time lags between the response in the summer mesopause and the dynamic activity in the winter: Karlsson et al. (2009) found a lag between the winter and the summer hemisphere of up to 15 days. In the monthly-mean approach that we use for this study, lags in time are not accounted for. Nevertheless, as seen in the figure, when winter GWs are absent (lower panels) the anomalous temperature responses in the summer polar mesosphere and in the winter polar stratosphere are opposing each other (Fig. 3c and d).

In terms of summer GW filtering and breaking, this opposing change in temperature response (Fig. $3 \mathrm{c}$ and d) can be understood by considering the anomalous response in the zonal flow. In Fig. 4a-c, we show the absolute vertical profiles of the summer zonal wind, the summer GW drag between $45-70^{\circ} \mathrm{N}$ and the summer temperatures between 60 $70^{\circ} \mathrm{N}$ for high (dashed black) and low (red) PW activity in the winter stratosphere for July when winter GWs are included. Figure $4 \mathrm{~d}-\mathrm{f}$ show the difference between the profiles: the case without GWs minus the control case. The anomalous responses, i.e. deviations about the 30-year mean, are shown in Fig. 4g-i. As can be seen in Fig. 4a, d and g, the westward stratospheric flow is slightly enhanced during high PW activity. An anomalous easterly flow will increase the intrinsic 
Run without GWs in the winter hemisphere
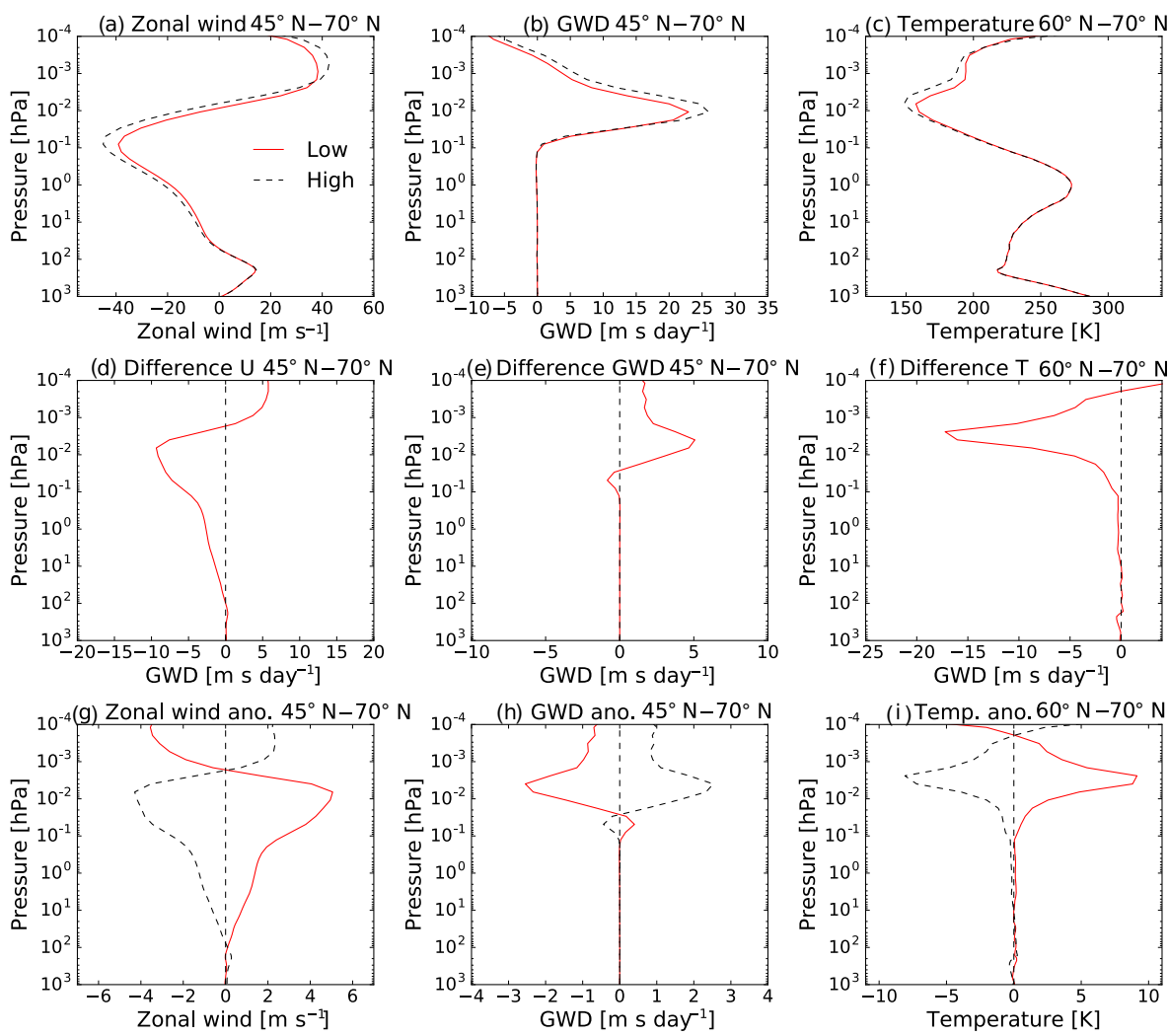

Figure 5. The July zonal wind (a, d, g) and the GW drag $(\mathbf{b}, \mathbf{e}, \mathbf{h})$ between $45-70^{\circ} \mathrm{N}$ and the temperature $(\mathbf{c}, \mathbf{f}, \mathbf{i})$ between $70-90^{\circ} \mathrm{N}$ for anomalously low and high temperatures in the winter stratosphere $\left(1-10 \mathrm{hPa}, 60-40^{\circ} \mathrm{S}\right)(\mathbf{a}-\mathbf{c})$ and the differences between them $(\mathbf{d}-\mathbf{f})$ and their anomalies $(\mathbf{g}-\mathbf{i})$, for the case where there are no GWs in the winter hemisphere. The red continuous lines show the results for anomalously low temperatures and the black dashed lines show the results for the anomalously high temperatures.
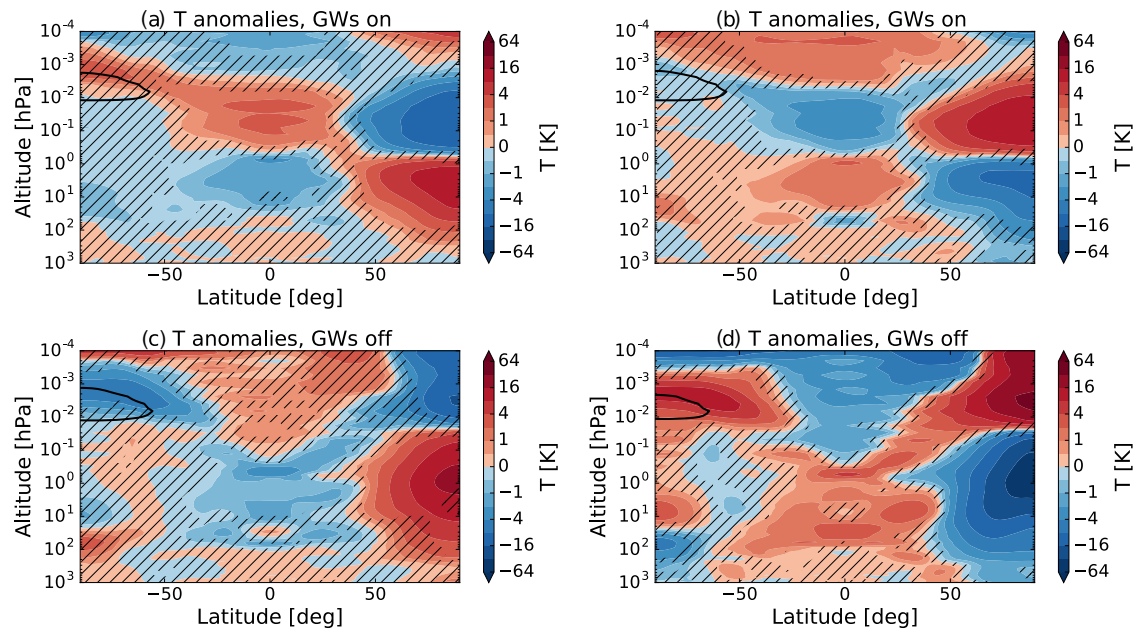

Figure 6. The temperature anomalies for high $(\mathbf{a}, \mathbf{c})$ and low $(\mathbf{b}, \mathbf{d}) \mathrm{PW}$ activity, as measured by the temperature in the winter stratosphere (1$\left.10 \mathrm{hPa}, 50-60^{\circ} \mathrm{N}\right)$ in January for the control run $(\mathbf{a}, \mathbf{b})$ and run without GWs in the winter hemisphere (c, d). There are 10 years of data with high temperature anomalies and 8 years with low temperature anomalies in the winter stratosphere for the control run. For the run without the GWs in the winter hemisphere, there are 7 years with high temperature anomalies and 5 years with low temperature anomalies. The hatched areas are regions where the data does not reach a confidence level of $95 \%$. The black $150 \mathrm{~K}$ contour indicates the polar mesopause region. 

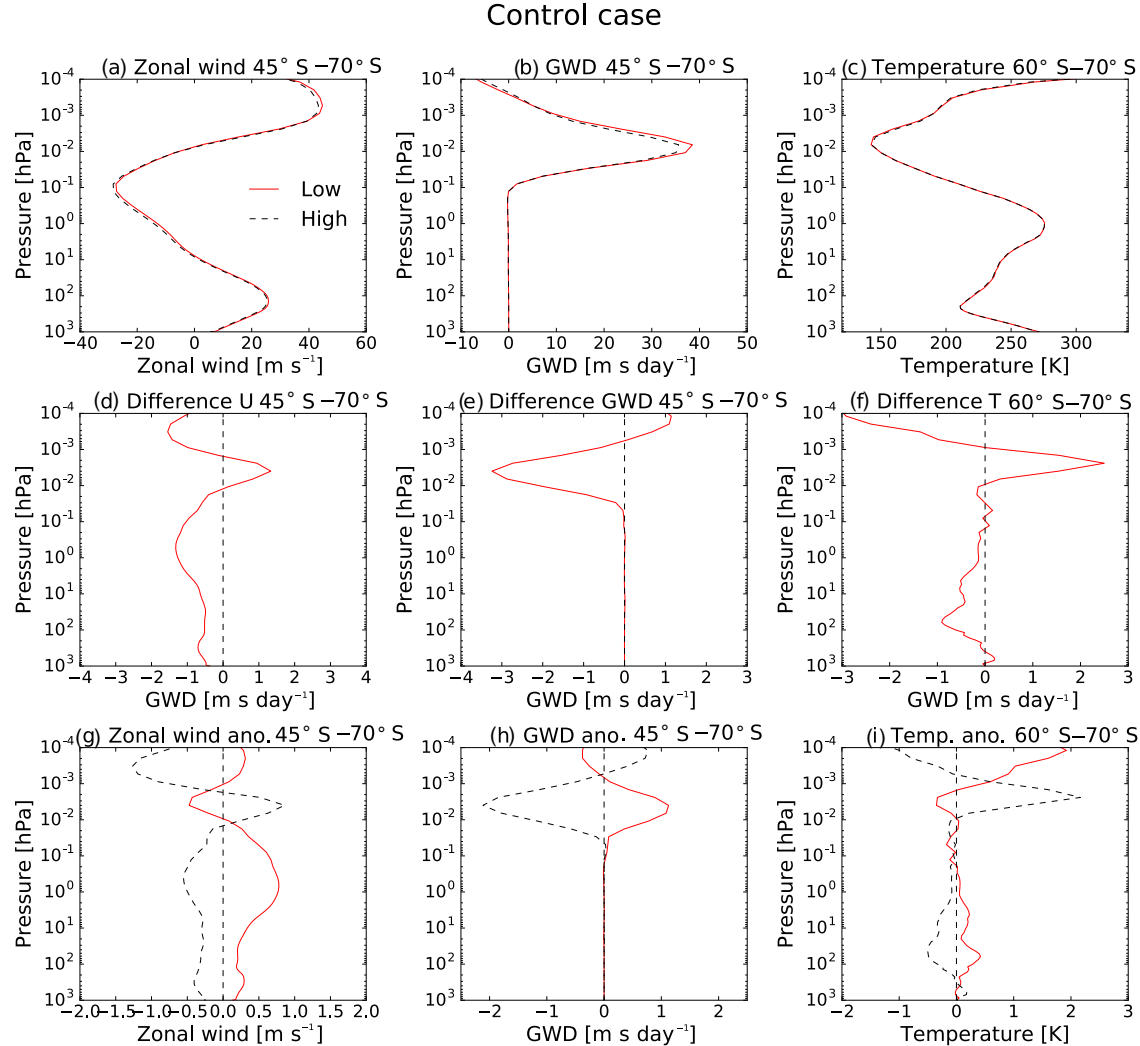

Figure 7. The January zonal wind (a, d, g) and the GW drag (b, e, h) between $45-70^{\circ} \mathrm{S}$ and the temperature $(\mathbf{c}, \mathbf{f}, \mathbf{i})$ between $60-70^{\circ} \mathrm{S}$ for anomalously low and high temperatures in the winter stratosphere $\left(1-10 \mathrm{hPa}, 50-60^{\circ} \mathrm{N}\right)(\mathbf{a}-\mathbf{c})$ and the differences between them $(\mathbf{d}-\mathbf{f})$ and their anomalies $(\mathbf{g}-\mathbf{i})$, for the case where there are GWs in the winter hemisphere. The red continuous lines show the results for anomalously low temperatures and the black dashed lines show the results for the anomalously high temperatures.

phase speed of the summer GWs carrying eastward momentum, which would result in an increase in the GWs breaking levels. However, at high PW activity, the mesospheric wind shear (from westward towards eastward) is stronger than at low PW activity, as illustrated in Fig. 4a, d and g, and results in a lowering of the GW breaking level in the mesosphere compared to calm winter stratospheric conditions (Fig. 4b, $\mathrm{e}$ and $\mathrm{h}$ ). As the GWs break lower, the adiabatic cooling of the summer polar mesopause is reduced, as seen in Fig. 4c, $\mathrm{f}$ and i. Additionally, it is worth pointing out that an intensification of the zonal wind shear would naturally lead to baroclinic instability and generation of Q2DWs.

Figure 5 shows profiles that are analogous to the ones illustrated in Fig. 4, but for the cases when winter GWs are absent. Note the differences in the wind profiles shown in Figs. 4 and 5. As described above, when the anomalous temperature response in the equatorial mesosphere is absent, the summer GWs carrying eastward momentum break slightly higher at high PW activity in the winter, as illustrated in Fig. $5 \mathrm{~b}, \mathrm{f}$ and $\mathrm{h}$ leading to an anomalously cooler mesosphere (Fig. 5c, f and i). Analogously, from Fig. 5, it is clear for a weak BDC (i.e. low PW activity), and therefore anomalously low temperatures in the SH winter stratosphere, the zonal winds in the stratosphere are less strongly westward. This leads to a weaker GW drag and a warmer NH summer mesopause region.

Our results show that without GWs in the SH winter hemisphere, the NH summer stratospheric variability - caused by the winter-side PW activity - has the major influence on the temperatures in the NH summer polar mesopause region. In the absence of the winter GWs, a dynamically active winter stratosphere leads to a cooling of the summer polar mesosphere instead of the warming associated with the conventional IHC mechanism. Moreover, our study indicates that if Q2DWs are solely generated by the strengthening of the easterly stratospheric summer jet, they are not likely to be the major contributor for warming the summer polar mesopause region during high $\mathrm{PW}$ events in the winter: if they were, a warming of this region in the absence of winter GWs would still occur. However, we suggest that the Q2DWs are also related to conventional IHC since the anomalous quadruple temperature response in the winter middle atmosphere at high PW wave activity (e.g. Fig. 3a) sharpens the wind shear between the stratosphere and the mesosphere in the summer hemisphere. 
Run without GWs in the winter hemisphere
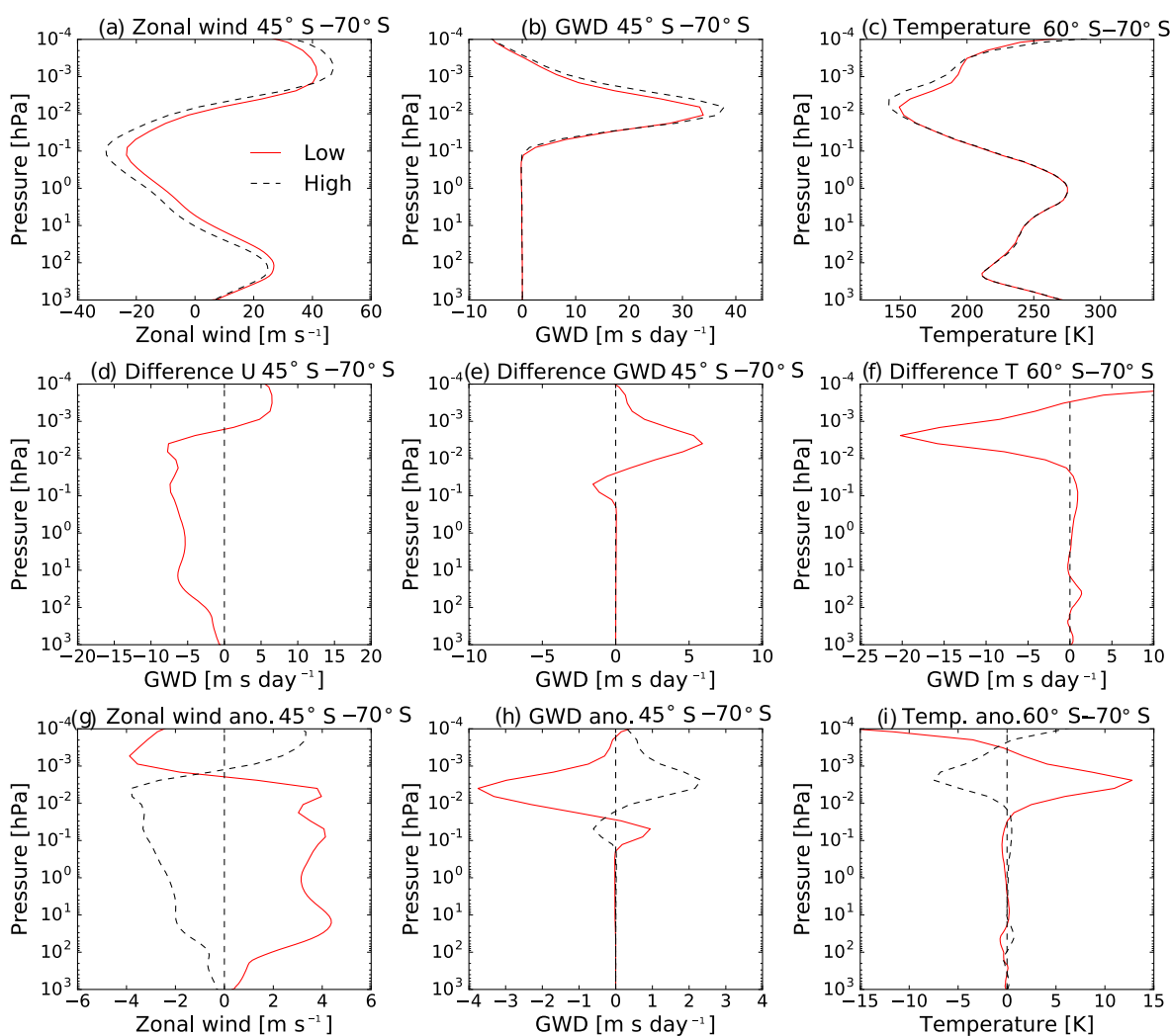

Figure 8. The January zonal wind (a, d, g) and the GW drag (b, e, h) between $45-70^{\circ} \mathrm{S}$ and the temperature (c, f, i) between $60-70^{\circ} \mathrm{S}$ for anomalously low and high temperatures in the winter stratosphere $\left(1-10 \mathrm{hPa}, 50-60^{\circ} \mathrm{N}\right)(\mathbf{a}-\mathbf{c})$ and the differences between them $(\mathbf{d}-\mathbf{f})$ and their anomalies $(\mathbf{g}-\mathbf{i})$, for the case where there are no GWs in the winter hemisphere. The red continuous lines show the results for anomalously low temperatures and the black dashed lines show the results for the anomalously high temperatures.

Figures 6-8 illustrate the same as Figs. 3-5, but for January conditions. Even though the statistical significance of the results is not as high as for July, the same chain of arguments apply.

We conclude that for both hemispheres, the effect of PW activity on the summer polar mesosphere temperatures would be the opposite if changes in the summer stratosphere were acting alone. Hence, the IHC as described by e.g. Karlsson et al. (2009) still holds as the dominant mechanism governing the monthly-mean temperature variability in the summer polar mesosphere, at least for July.

\section{Conclusive summary}

In this study, the IHC mechanism and the role of the summer stratosphere in shaping the conditions of the summer polar mesosphere have been investigated. For the purpose, we have utilized the widely used WACCM model to carry out sensitivity experiments in the same manner as Karlsson and Becker (2016): the mesospheric residual flow in the winter hemisphere was dramatically diminished by removing win- ter GWs. This setting allows for studying the effect of summer stratospheric variability alone, i.e. without considering any influences from the winter mesospheric flow.

In accordance with Karlsson and Becker (2016), we find that the summer polar mesopause region would be substantially warmer without the GW-driven residual circulation in the winter. Additionally, as for the KMCM experiment, using WACCM we find that the IHC mechanism has a net cooling effect on the summer mesospheres differing in magnitude between the two hemispheres, although the signal in WACCM does not reach statistical significance all the way to the poles. The mechanism plays a more important role affecting the temperatures in the NH summer mesopause compared to the SH.

In the absence of winter GWs - hence without the winter mesospheric residual circulation - the variability in the summer polar mesosphere is determined by the temperature gradient in the summer stratosphere below. However, the response opposes that of the conventional IHC: it is found that in the absence of winter GWs, low PW activity in the winter hemisphere leads to a warming of the summer polar meso- 
sphere region for both the $\mathrm{NH}$ and the $\mathrm{SH}$. Our results again confirm the idea that the IHC mechanism - with the equatorial mesosphere playing a crucial role - has a significant influence on the temperatures in the summer mesopause regions.

The Q2DW, a common feature in the summer mesosphere, is associated with an enhancement of the easterly flow in the summer stratosphere. The influence by these waves on the summer polar mesosphere can be rather dramatic. Nevertheless, our study shows that in a statistical sense, these events are of less importance for the summer polar mesosphere, at least if generated by the stratospheric flow alone. This conclusion is drawn from noting that anomalous easterly flow in the stratosphere gives rise to a cooling of the summer polar mesosphere if the mesospheric winter residual flow is absent. From this finding we suggest that the generation of the Q2DW is facilitated not only by an increase in the easterly summer stratospheric jet but also by the conventional IHC mechanism, which increases the zonal wind shear between the summer stratosphere and mesosphere.

Data availability. Data sets are available upon request by contacting the corresponding author.

Competing interests. The authors declare that they have no conflict of interest.

Acknowledgements. The authors would like to thank Hamish Struthers at the Swedish National Supercomputer Centre (NSC) for his assistance concerning the technical aspects of the WACCM runs on Triolith. We also thank the two anonymous reviewers for their insightful comments.

Edited by: Bernd Funke

Reviewed by: two anonymous referees

\section{References}

Andrews, D. G., Holton, J. R., and Leovy, C. B.: Middle atmosphere dynamics, Academic Press, USA, 1987.

Becker, E. and Fritts, D. C.: Enhanced gravity-wave activity and interhemispheric coupling during the MaCWAVE/MIDAS northern summer program 2002, Ann. Geophys., 24, 1175-1188, https://doi.org/10.5194/angeo-24-1175-2006, 2006.

Becker, E. and Schmitz, G.: Climatological effects of orography and land-sea contrasts on the gravity wave-driven circulation of the mesosphere, J. Atmos. Sci., 60, 103-118, https://doi.org/10.1175/15200469(2003)060<0103:CEOOAL>2.0.CO;2, 2003.

Becker, E., Müllermann, A., Lübken, F.-J., Körnich, H., Hoffmann, P., and Rapp, M.: High Rossby-wave activity in austral winter 2002: Modulation of the general circulation of the MLT during the MaCWAVE/MIDAS north- ern summer program, Geophys. Res. Lett., 31, L24S03, https://doi.org/10.1029/2004GL019615, 2004.

Becker, E., Knöpfel, R., and Lübken, F.-J.: Dynamically induced hemispheric differences in the seasonal cycle of the summer polar mesopause, J. Atmos. Sol.-Terr. Phy., 129, 128-141, https://doi.org/10.1016/j.jastp.2015.04.014, 2015.

De Wit, R. J., Janches, D., Fritts, D. C., and Hibbins, R. E.: QBO modulation of the mesopause gravity wave momentum flux over Tierra del Fuego, Geophys. Res. Lett., 43, 4094-4055, https://doi.org/10.1002/2016GL068599, 2016.

Espy, P. J., Ochoa Fernández, S., Forkman, P., Murtagh, D., and Stegman, J.: The role of the QBO in the inter-hemispheric coupling of summer mesospheric temperatures, Atmos. Chem. Phys., 11, 495-502, https://doi.org/10.5194/acp-11-495-2011, 2011.

Fritts, D. C. and Alexander, M. J.: Gravity wave dynamics and effects in the middle atmosphere, Rev. Geophys., 41, 1003 , https://doi.org/10.1029/2001RG000106, 2003.

Garcia, R. R. and Solomon, S.: The effect of breaking gravity waves on the dynamics and chemical composition of the mesosphere and lower thermosphere, J. Geophys. Res., 90, 38503868, https://doi.org/10.5194/10.1029/JD090iD02p03850, 1985.

Gu, S.-Y., Liu, H.-L., Li, T., Dou, X., Wu, Q., and Russell III, J. M.: Evidence of nonlinear interactions between quasi 2 day wave and quasi-stationary wave, J. Geophys. Res., 120, 1256-1263, https://doi.org/10.5194/10.1002/2014JA020919, 2015.

Gu, S.-Y., Liu, H.-L., Pedatella, N. M., Dou, X., Li, T., and Chen, T.: The quasi 2 day wave activities during 2007 austral summer period as revealed by the Whole Atmosphere Community Climate Model, J. Geophys. Res.-Space, 121, 2743-2754, https://doi.org/10.1002/2015JA022225, 2016.

Gumbel, J. and Karlsson, B.: Intra- and inter-hemispheric coupling effects on the polar summer mesosphere, Geophys. Res. Lett., 38, L14804, https://doi.org/10.1029/2011GL047968, 2011.

Haurwitz, B.: Frictional effects and the meridional circulation in the mesosphere, J. Geophys. Res., 66, 2381-2391, https://doi.org/10.1029/JZ066i008p02381, 1961.

Holton, J. R.: The role of gravity wave induced drag and diffusion in the momentum budget of the mesosphere, J. Atmos. Sci., 39, 791-799, https://doi.org/10.1175/15200469(1982)039<0791:TROGWI >2.0.CO;2, 1982.

Holton, J. R.: The influence of gravity wave breaking on the general circulation of the middle atmosphere, J. Atmos. Sci., 40, 2497-2507, https://doi.org/10.1175/15200469(1983)040<2497:TIOGWB>2.0.CO;2, 1983.

Karlsson, B. and Becker, E.: How does interhemispheric coupling contribute to cool down the summer polar mesosphere?, J. Climate, 29, 8807-8821, https://doi.org/10.1175/JCLI-D-160231.1, 2016.

Karlsson, B., Körnich, H., and Gumbel, J.: Evidence for interhemispheric stratosphere-mesosphere coupling derived from noctilucent cloud properties, Geophys. Res. Lett., 34, L16806, https://doi.org/10.1029/2007GL030282, 2007.

Karlsson, B., McLandress, C., and Shepherd, T. G.: Interhemispheric mesospheric coupling in a comprehensive middle atmosphere model, J. Atmos. Sol.-Terr. Phy., 71, 518-530, https://doi.org/10.1016/j.jastp.2008.08.006, 2009.

Körnich, H. and Becker, E.: A simple model for the interhemispheric coupling of the middle atmo- 
sphere circulation, Adv. Space Res., 45, 661-668, https://doi.org/10.1016/j.asr.2009.11.001, 2010.

Lindzen, R. S.: Turbulence stress owing to gravity wave and tidal breakdown, J. Geophys. Res., 86, 9707-9714, https://doi.org/10.1029/JC086iC10p09707, 1981.

Lübken, F.-J., Von Zahn, U., Manson, A., Meek, C., Hoppe, U.-P., Schmidlin, F. J., Stegman, J., Murtagh, D. P., Rüster, R., Schmitz, G., Widdel, H.-U., and Espy, P.: Mean state densities, temperatures and winds during the MAC/SINE and MAC/EPSILON campaigns, J. Atmos. Sol.-Terr. Phy., 52, 955970, https://doi.org/10.1016/0021-9169(90)90027-K, 1990.

Marsh, D. R., Mills, M. J., Kinnison, D. E., Lamarque, J. F., Calvo, N., and Polvani, L. M.: Climate change from 1850 to 2005 simulated in CESM1(WACCM), J. Climate, 26, 7372-7391, https://doi.org/10.1175/JCLI-D-12-00558.1, 2013.

McFarlane, N. A.: The effect of orographically excited wave drag on the general circulation of the lower stratosphere and troposphere, J. Atmos. Sci., 44, 1775-1800, https://doi.org/10.1175/15200469(1987)044<1775:TEOOEG>2.0.CO;2, 1987.

Neale, R., Richter, J., Park, S., Lauritzen, P., Vavrus, S., Rasch, P., and Zhang, M.: The mean climate of the Community Atmosphere Model (CAM4) in forced SST and fully coupled experiments, J. Climate, 26, 5150-5168, https://doi.org/10.1175/JCLID-12-00236.1, 2013.

Pendlebury, D.: A simulation of the quasi-two-day wave and its effect on variability of summertime mesopause temperatures, J. Atmos. Sol.-Terr. Phy., 80, 138-151, https://doi.org/10.1016/j.jastp.2012.01.006, 2012.
Richter, J. H., Sassi, F., and Garcia, R. R.: Toward a physically based gravity wave source parameterization in a general circulation model, J. Atmos. Sci., 67, 136-156, https://doi.org/10.1175/2009JAS3112.1, 2010.

Salby, M. L. and Callaghan, P. F.: Seasonal Amplification of the 2Day Wave: Relationship between Normal Mode and Instability, J. Atmos. Sci., 58, 1858-1869, 2001.

Sassi, F., Kinnison, D., Boville, B. A., Garcia, R. R., and Roble, R.: Effect of El Niño-Southern Oscillation on the dynamical, thermal, chemical structure of the middle atmosphere, J. Geophys. Res., 109, D17108, https://doi.org/10.1029/2003JD004434, 2004.

Shepherd, T. G.: The middle atmosphere, J. Atmos. Sol.-Terr. Phy., 62, 1587-1601, https://doi.org/10.1016/S1364-6826(00)00114$0,2000$.

Siskind, D. E. and McCormack, J. P.: Summer mesospheric warmings and the quasi 2 day wave, Geophys. Res. Lett., 41, 717-722, https://doi.org/10.1002/2013GL058875, 2014.

Siskind, D. E., Stevens, M. H., Hervig, M., Sassi, F., Hoppel, K., Englert, C. R., and Kochenas, A. J.: Consequences of recent Southern Hemisphere winter variability on polar mesospheric clouds, J. Atmos. Sol.-Terr. Phy., 73, 2013-2021, https://doi.org/10.1016/j.jastp.2011.06.014, 2011.

Tan, B., Chu, X., Liu, H.-L., Yamashita, C., and Russell III, J. M.: Zonal-mean global teleconnections from 15 to $110 \mathrm{~km}$ derived from SABER and WACCM, J. Geophys. Res., 117, D10106, https://doi.org/10.1029/2011JD016750, 2012.

Wu, D. L., Fishbein, E. F., Read, W. G., and Waters, J. W.: Excitation and evolution of the quasi-2-day-wave observed in UARS/MLS temperature measurements, J. Atmos. Sci., 53, 728-738, https://doi.org/10.1175/15200469(1996)053<0728:EAEOTQ>2.0.CO;2, 1996. 